\title{
COMMITTEE ON AVAILABLE TEACHERS OF COLLEGIATE MATHEMATICS
}

The Committee on Available Teachers of Collegiate Mathematics, established by the War Policy Committee of the American Mathematical Society and the Mathematical Association of America, has been in existence since the beginning of April, 1943. During this time it has received and answered numerous inquiries from colleges and universities needing teachers of mathematics, as well as from teachers who were free to accept appointments.

A total of 149 persons have registered with the Committee. Of this number, 129 have at least the master's degree. The Committee has answered requests for teachers of mathematics from 67 different institutions. To these institutions a total of 348 names, representing 111 different persons, have been suggested. According to the Committee's records, 57 of the persons registered are no longer available. It should be pointed out that of the remaining candidates some have indicated that they are available only for summer or part-time teaching, others have had only secondary school teaching experience, while others are available for appointment in restricted geographical areas.

It is anticipated that the demand for teachers will increase considerably during the next two or three months. On the other hand, the number of available well-qualified candidates who have registered with the Committee for such appointments has been reduced to such an extent that the remaining supply has become quite inadequate to meet the expected demand.

For this reason, the committee requests that (a) individual teachers report their availability and (b) departments of mathematics inform the Committee at the earliest possible date of their needs during the next half year, giving as full details as they can concerning the qualifications expected, the salary offered and other pertinent facts relating to their vacancies, and of members who are free to fill temporary positions in other institutions.

The effectiveness of the work of this Committee will be enhanced if registrants will report positions which they have accepted and if inquiring institutions will report appointments that have been made.

Committee on Available Teachers, 110 Bennett Hall, University of Pennsylvania

W. D. CAIRNS

ARNOLD DRESDEN

September 2, 1943.

J. R. KLINE 